\title{
Foucher's antegrade intramedullary fixation of fractures of the fifth metacarpal
}

\author{
SM Safadi MD, MM Al-Qattan FRCSC \\ Divisions of Orthopaedics and Plastic Surgery, Al-Hammadi Hospital and King Khalid University \\ Hospital - King Saud University, Riyadh, Saudi Arabia
}

SM Safadi, MM Al-Qattan. Foucher's antegrade intramedullary fixation of fractures of the fifth metacarpal. Can J Plast Surg 1997;5(4):238-240. Experience with six consecutive patients who were treated with antegrade intramedullary $\mathrm{K}$ wire fixation for fifth metacarpal fractures is presented. Differences between the original Foucher's technique and other modified techniques are discussed. Modified Foucher's technique is simple and has a low complication rate. However, secondary wire removal (elective or otherwise) should be discussed with all patients preoperatively.

Key Words: Fixation, Fracture, Metacarpal bone

\section{Immobilisation intramédullaire antérograde de Foucher dans un cas de fracture de la cinquième articulation métacarpienne}

RÉSUMÉ : On présente ici l'expérience de l'auteur auprès de six patients consécutifs traités au moyen d'une fixation intramédullaire antérograde par broche en K pour fracture de la cinquième articulation métacarpienne. Les différences entre la technique originale de Foucher et d'autres techniques modifiées sont présentées ici. La technique modifiée de Foucher est simple et s'accompagne d'un faible taux de complications. Toutefois, le retrait secondaire de la broche (électif ou autre) doit être abordé avec tous les patients avant l'opération.

$I_{n}^{n}$ n a recent communication Foucher (1) reviewed his technique of antegrade intramedullary fixation of fractures of the fifth metacarpal. This technique has gained popularity in Europe over the past 20 years (2). More recently, Gonzalez et al (2) described a modified technique and applied it to both metacarpal and proximal phalangeal fractures $(3,4)$. This paper describes our experience with this method in Saudi Arabia.

\section{PATIENTS AND METHODS}

Six consecutive patients who were treated with antegrade intramedullary fixation of fifth metacarpal fractures were retrospectively reviewed. All patients were males, and the fractures were sustained after striking another person or an object. The average age was 26 years (range 22 to 33). Four

Correspondence and reprints: Dr Al-Qattan, PO Box 18097, Riyadh 11415, Saudi Arabia. Telephone 11-9661-456-9604, fax 11-9661-467-9493 injuries involved the rihght hand and two involved the left. All fractures were closed. Four patients had metaphyseal (neck) fractures and the remaining two had metaphyseal fractures that extended to the diaphysis (metaphyseal-diaphyseal). The indication for operative fixation was inability to maintain an acceptable position (palmar angulation of less than $40^{\circ}$ using closed reduction and plaster immobilization.

\section{Operative technique}

A $2 \mathrm{~cm}$ incision is made proximal to the base of the fifth metacarpal. The dorsal cutaneous branches of the ulnar nerve are identified and protected. A hole is made with an awl through the ulnar cortex of the metacarpal base to access the medullary canal. The fracture is reduced by flexing the metacarpophalangeal and proximal interphalangeal joints and then exerting upwards pressure through the proximal phalanx and downward pressure on the metacarpal shaft.

For metaphyseal fractures, a single round-tip $\mathrm{K}$ wire $\left(1.8 \mathrm{~mm}\right.$ or $2 \mathrm{~mm}$ ) is gently curved (about $15^{\circ}$ ) and driven 
through the medullary canal until the blunt tip of the wire engages the subchondral bone of the metacarpal head (Figure 1). For metaphyseal-diaphyseal fractures, two round-tip $\mathrm{K}$ wires $(1.4 \mathrm{~mm})$ are successively driven through the medullary canal in divergent directions (Figure 2). The proximal ends of the wires are bent and cut, leaving sufficient length to allow secondary removal when necessary.

A light bandage dressing is applied, and mobilization is started the next day with buddy tapping of the little and ring fingers.

All patients were followed up for more than six months postoperatively (mean one year). All fractures healed with no secondary fracture displacements. All patients regained full range of motion of the fingers. There were no cases of hematomas, extensor tendon injury, reflex sympathetic dystrophy, dorsal ulnar nerve neuromas, or rotational or scissoring deformities. One patient felt slight pain on ulnar deviation of the wrist because the proximal end of the wires impinged on the carpus; secondary removal of the $\mathrm{K}$ wires relieved the pain. Another patient sustained a second trauma to the base of the fifth metacarpal five months postoperatively. The bone did not refracture but there was evidence of localized superficial infection at the proximal end of the $\mathrm{K}$ wire. Secondary removal of the wire and oral antibiotics resulted in complete resolution of the infection.

\section{DISCUSSION}

The treatment of fractures of the fifth metacarpal neck is controversial and varies from no treatment to a variety of methods for internal fixation (5). Foucher's technique (1) of antegrade intramedullary fixation has several advantages: it is simple, maintains the reduction without opening the fracture site and allows early mobilization through a full range of motion.

There are several differences among the techniques described by Foucher (1), Gonzalez and co-workers (3) and our technique outlined above (Table 1).
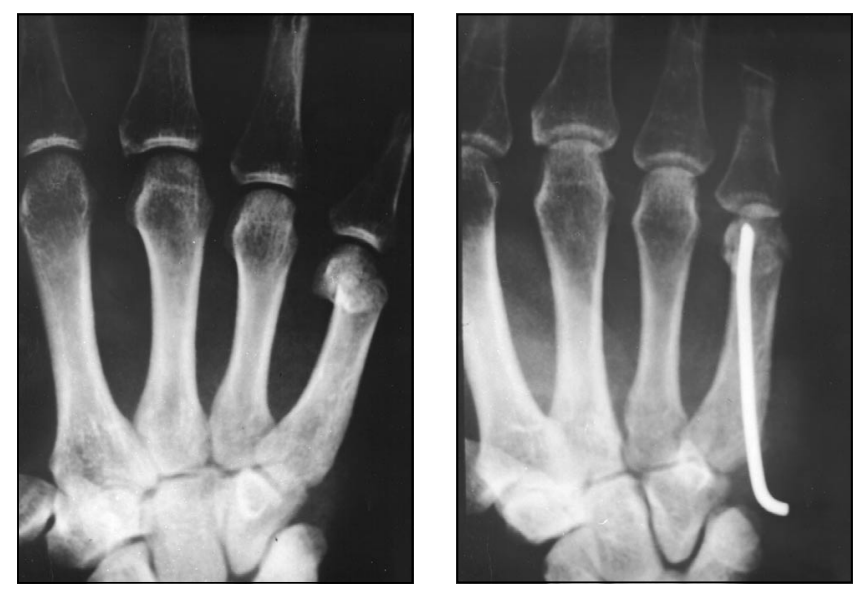

Figure 1) Left Hand before treatment; Right A single $1.8 \mathrm{~mm} \mathrm{~K}$ wire is used to fix metaphyseal fractures


Figure 2) Left Hand before treatment; Right $T$ wo $1.4 \mathrm{~mm} \mathrm{~K}$ wires are used to fix metaphyseal-diaphyseal fractures

Our modified technique has been used for many years at the University of Paris, and one of us had previously studied 25 consecutive patients treated in Paris (5). In that series, five

\section{TABLE 1}

\section{Antegrade intramedullary fixation of fractures of the fifth metacarpal neck}

\section{Technique}

\section{Feature}

Incision

Access to the medullary cavity

Intra-operative radiography

$K$ wires used for each fracture
Foucher (reference 1)

Proximal to the metacarpal base

A single hole through the ulnar cortex

Not used

Three (occasionally two) $0.8 \mathrm{~mm}$ wires
Gonzalez et al (references 3,4)

Over the metacarpal base

Four drill holes through the dorsal cortex

Used

Four or five $0.8 \mathrm{~mm}$ wires

Clam-digger splint with MP joints flexed $90^{\circ}$

PIP and DIP joints are mobilized immediately. MP joints are mobilized at four weeks

No

\section{As presented in this paper}

Proximal to the metacarpal base

A single hole through the ulnar cortex

Not used

A single 1.8 to $2 \mathrm{~mm}$ wire for metaphyseal fractures and two $1.4 \mathrm{~mm}$ wires for metaphyseal-diaphyseal fractures

Light bandage

MP, PIP and DIP joints are mobilized the next day

Only when necessary 
TABLE 2

Complications following antegrade intramedullary fixation of fractures of the fifth metacarpal

\begin{tabular}{|c|c|c|c|}
\hline \multirow[b]{2}{*}{ Complication } & \multicolumn{2}{|c|}{$\begin{array}{c}\text { Foucher's technique } \\
\text { ( } n=260 \text { patients })^{\star}\end{array}$} & \multirow{2}{*}{$\begin{array}{c}\text { Modified } \\
\text { Foucher's } \\
\text { technique } \\
(n=31 \\
\text { patients })^{\dagger}\end{array}$} \\
\hline & $\begin{array}{c}\text { Treated by } \\
\text { Foucher } \\
(n=66)\end{array}$ & $\begin{array}{c}\text { Treated } \\
\text { by other } \\
(n=194)\end{array}$ & \\
\hline $\begin{array}{l}\text { Reflex sympathetic } \\
\text { dystrophy }\end{array}$ & 1 & - & - \\
\hline Dorsal ulnar neuritis & 1 & - & - \\
\hline Hematomas & - & - & - \\
\hline Infections & - & 1 & 1 \\
\hline $\begin{array}{l}\text { Secondary fracture } \\
\text { displacement }\end{array}$ & - & 2 & - \\
\hline Scissoring deformity & - & - & - \\
\hline $\begin{array}{l}\mathrm{K} \text { wire protrusion through } \\
\text { the MP joint }\end{array}$ & - & 5 & - \\
\hline $\begin{array}{l}\text { Extensor tendon rupture } \\
\text { over the proximally } \\
\text { protruding wires }\end{array}$ & - & 1 & - \\
\hline $\begin{array}{l}\text { Impingement of the } \\
\text { proximal ends of the } \\
\text { wires on the carpus }\end{array}$ & - & - & $6^{\ddagger}$ \\
\hline
\end{tabular}

*Sixty-six patients were treated by Foucher and the remaining 194 cases were published in the European literature and reviewed by Foucher (1); ${ }^{\dagger}$ Twenty-five patients were treated in Paris and the remaining six in Saudi Arabia; ${ }^{\ddagger}$ This complication is seen only in the modified technique because elective secondary removal of the wires is not performed. MP Metacarpophalangeal patients required secondary wire removal because the proximal end of the wires impinged on the carpus.

The total number of complications seen in 260 patients treated by the Foucher's technique and 31 patients treated by our modified technique are summarized in Table 2. Results using the technique of Gonzalez et al (3) are not included in the table because in their report complications of fifth metacarpal fractures were combined with complications of fractures of the other metacarpals.

\section{CONCLUSIONS}

When the hand surgeon feels that there is an indication for fixation of a displaced fifth metacarpal neck fracture, antegrade intramedullary fixation is a simple and effective method of osteosynthesis with a low complication rate. However, secondary wire removal (elective or otherwise) should be discussed with all patients preoperatively.

\section{REFERENCES}

1. Foucher G. "Bouquet" osteosynthesis in metacarpal neck fractures: A series of 66 patients. J Hand Surg 1995;20A(Suppl):S86-S90.

2. Safadi S. Traitment des fractures du col du 5e metacapien par enclouage selon la methode de Foucher (A propos de 25 cas). Paris: University of Paris, 1986. (Thesis)

3. Gonzalez MH, Igram CM, Hall RF. Flexible intramedullary nailing for metacarpal fractures. J Hand Surg 1995;20A:382-7.

4. Gonzalez MH, Igram CM, Hall RF. Intramedullary nailing of proximal phalangeal fractures. J Hand Surg 1995;20A:808-12.

5. Ford DJ, Ali M S, Steel WM. Fractures of the fifth metacarpal neck: Is reduction or immobilisation necessary? J Hand Surg 1989;14B:165-7. 